\title{
Anatomia comparada do lenho de Xylopia aromatica (Lam.) Mart. em áreas de cerrado e de plantação de Pinus elliottii Engelm.
}

\author{
AGNES E. LUCHI ${ }^{1,2}$, LUIZ C. PEREIRA SILVA ${ }^{1}$ e MARCELO A. MORAES ${ }^{1}$
}

(recebido: 31 de março de 2005; aceito: 10 de novembro de 2005)

\begin{abstract}
Comparative wood anatomy of Xylopia aromatica (Lam.) Mart. in "cerrado" and plantation area of Pinus elliottii Engelm.). The anatomical structure of Xylopia aromatica (Lam.) Mart. wood was analyzed comparing stem and root samples from a caracteristic "cerrado" area, and another area with cultivated monoculture of Pinus elliotti Engelm. Both areas are inside the "Reserva Biológica e Estação Experimental de Moji-Guaçu". The samples were collected by non-destructive method. The quantitative analyzed characteristics data were obtained by counting and measuring in vessel elements, fibers, axial and radial parenchyma, in both histological sections and dissociated tissue. These data were submitted to the no parametric proof of Mann-Whitney that showed significant differences for 12 of the 18 analyzed characteristics. Among these, only intervessel pits diameter, vessel-ray pits diameter, and axial parenchyma percentage, showed larger averages for the plantation area specimens. Soil moisture data were obtained together with water soil retention curve. The structural analysis demonstrated the presence of growth rings delimited by radially flattened walls fibres observed in all studied specimens. This characteristic indicates a physiologic and anatomical adaptation of specimens to the drought period that occurs annually in the region. The low secretory idioblast occurrence in plantation area specimens indicates the possible physiologic alterations induced by the presence of Pinus elliottii plantation in "cerrado" area.
\end{abstract}

Key words - "cerrado", plantation Pinus, wood anatomy, Xylopia aromatica

RESUMO - (Anatomia comparada do lenho de Xylopia aromatica (Lam.) Mart. em áreas de cerrado e de plantação de Pinus elliottii Engelm.). A estrutura anatômica do lenho de Xylopia aromatica (Lam.) Mart. foi analisada pela observação do caule e da raiz de espécimes provenientes de duas áreas de cerrado, uma com vegetação característica e outra, em que a vegetação original foi substituída por monocultura de Pinus elliotti Engelm. As duas áreas situam-se na Reserva Biológica e Estação Experimental de Moji-Guaçu. As amostras foram coletadas pelo método não destrutivo. Os dados quantitativos das características analisadas foram obtidos mediante contagens e medições nos elementos de vasos, fibras e parênquima axial e radial, através das secções histológicas e tecido dissociado. Esses dados foram submetidos à prova não paramétrica de Mann-Whitney que mostrou diferenças significativas para 12 das 18 características analisadas. Dentre essas, apenas o diâmetro das pontoações intervasculares e das radiovasculares e a porcentagem de parênquima axial, apresentaram médias maiores para os espécimes da área de plantio. A análise estrutural do lenho demonstrou a presença de anéis de crescimento, delimitados pelo achatamento das paredes radiais das fibras, observada em todos os espécimes, indicando uma adaptação fisiológica e anatômica ao período de seca que ocorre anualmente na região. A baixa ocorrência de idioblastos secretores, nos espécimes da área de plantio, fornece indício sobre as possíveis alterações fisiológicas induzidas pela presença da plantação de Pinus elliottii em área de cerrado.

Palavras-chave - anatomia de lenho, cerrado, plantação de Pinus, Xylopia aromatica

\section{Introdução}

A anatomia ecológica do lenho abrange o estudo das influências ambientais sobre as variações estruturais de espécies lenhosas. As relações entre estrutura da madeira e as características climáticas têm sido amplamente estudadas, sendo Baas (1973) e Carlquist (1975) os pioneiros nesses estudos. Trabalhos posteriores, desenvolvidos em exemplares, tanto de regiões temperadas quanto tropicais (Baas et al. 1983,

\footnotetext{
1. Instituto de Botânica, Seção de Anatomia e Morfologia, Caixa Postal 4005, 01061-970 São Paulo, SP, Brasil.

2. Autor para correspondência: aeluchi@ibot.sp.gov.br
}

Carlquist \& Hoekman 1985, Baraja-Morales 1985, Gomes \& Muniz 1986, Baas \& Schweingruber 1987), constataram, também, que as variações ambientais se refletem na estrutura do lenho.

Os estudos sobre anatomia ecológica do lenho no Brasil são ainda escassos e neles são comparadas, geralmente, as características dos elementos celulares de espécies de ambientes mésicos com aqueles de ambientes xéricos (Matto Filho 1971, 1989, Alves \& Angyalosy-Alfonso 2000, Marcati et al. 2001), ou ainda, estabelecem um paralelo com espécies de ambientes com maior disponibilidade hídrica, como as matas ciliares (Mazzoni-Viveiros \& Luchi 1989, Luchi 1990, Luchi 1998, Luchi 2004a, b). 
A vegetação de cerrado apresenta uma diversidade de plantas superiores em torno de 10.000 espécies (Ratter 2004), das quais aproximadamente metade são endêmicas.

Estima-se que aproximadamente $37 \%$ da área do bioma do cerrado já perdeu sua cobertura primitiva, sendo ocupada por diferentes paisagens antrópicas, basicamente mono ou oligoculturas exóticas (Dias 1994).

No Estado de São Paulo, o cerrado foi, em grande parte, substituído pela pecuária ou agricultura, apesar de ser considerado um dos centros de diversidade do cerrado brasileiro (Gomes et al. 2004).

O gênero Pinus, mundialmente utilizado para produção florestal, é considerado de altíssima capacidade invasora (Richardson 1999), com diversas espécies representando, atualmente, problemas de invasão biológica na Argentina, Paraguai, Uruguai, Chile, Havaí, Austrália, Nova Zelândia e África do Sul. A invasão biológica, processo de introdução e adaptação de espécies exóticas que se naturalizam, tornando-se dominantes, altera a fisionomia e a função dos ecossistemas naturais, levando as populações nativas à perda de espaço e ao declínio genético (Ziller 2000).

$\mathrm{Na}$ área de estudo com o plantio de Pinus ocorrem, espontânea e esparsamente, algumas espécies remanescentes da vegetação nativa, formando um subbosque não característico. Entre elas evidenciam-se diversos espécimes de Xylopia aromatica (Lam.) Mart., que sobrevivem à sombra dos pinheiros.

Xylopia aromatica é uma planta semidecídua, heliófita, pioneira e seletiva xerófita, característica do cerrado e campo cerrado (Lorenzi 1992). Apesar da vegetação de cerrado ser extremamente heterogênea, Xylopia aromatica foi uma das 38 espécies de ocorrência em $50 \%$ ou mais na composição da vegetação lenhosa de cerrado em 376 áreas analisadas por Ratter et al. (2003), dentre um total de 951 espécies.

$O$ interesse no conhecimento da estrutura anatômica de Xylopia aromatica, desenvolvida dentro de uma monocultura de gimnosperma exótica, constituiu o objetivo deste trabalho.

\section{Material e métodos}

O presente estudo foi desenvolvido em duas áreas de cerrado, uma com vegetação característica, pertencente à Reserva Biológica de Moji-Guaçu, sob a responsabilidade administrativa do Instituto de Botânica de São Paulo, e a outra, situada na Estação Ecológica de Moji-Guaçu, antiga Fazenda Campininha, administrada pelo Instituto Florestal de São Paulo, onde a vegetação característica de cerrado foi substituída por monocultura de Pinus elliottii Engelm. As duas áreas de estudo situam-se no distrito de Martinho Prado Junior, no Município de Moji-Guaçu, São Paulo, Brasil.

Embora não sendo um substituto ideal para a vegetação nativa, devido às funções que a mesma desempenha no ecossistema, o cultivo de P. eliottii tem sido praticado com freqüência em áreas de cerrado para fins de extração econômica de resina. Segundo Golfari (1967) e Brasil et al. (1980), o plantio dessa essência florestal é inadequado nessa região fitogeográfica, uma vez que a baixa precipitação no inverno, característica típica das áreas do cerrado, por si só, representa uma condição limitante ao adequado desenvolvimento da espécie.

O clima da região, segundo o sistema de Köppen, é do tipo Cwa, úmido quente, de inverno seco, com temperaturas médias acima de $22^{\circ} \mathrm{C}$ no mês mais quente e acima de $18^{\circ} \mathrm{C}$ no mês mais frio. A pluviosidade média é de $250 \mathrm{~mm}$ em janeiro, mês mais chuvoso, e inferior a $30 \mathrm{~mm}$ em julho, mês mais seco, aparentemente com duas estações bem definidas (Setzer 1946, 1966).

As amostras utilizadas, do lenho do caule e da raiz (tabela 1), foram retiradas através de método não destrutivo de seis espécimes de Xylopia aromatica (Lam.) Mart., sendo três na área característica de cerrado, e três na área com plantio de Pinus elliottii, (figura 1). As amostras de caule foram coletadas a altura do peito $(1,30 \mathrm{~m}$ do solo), utilizando-se serrote, formão e martelo, e as de raiz foram coletadas, com serrote, a aproximadamente $0,30 \mathrm{~m}$ de profundidade no solo. Todas as amostras foram registradas e depositadas na Xiloteca do Instituto de Botânica da Secretaria do Meio Ambiente do Estado de São Paulo (SPw). De cada amostra foi confeccionado um corpo de prova para a obtenção das seções histológicas em micrótomo de deslize, nos planos transversal, longitudinal tangencial e longitudinal radial e variaram de 15 a $20 \mu \mathrm{m}$ de espessura. As seções foram coradas e montadas conforme técnicas usuais de anatomia de madeira (Johansen 1940, Sass 1951), sendo que parte da amostra do lenho foi utilizada para obtenção do tecido macerado (teste de Franklin, modificado por Normand 1972).

Tabela 1. Dados das amostras de Xylopia aromatica (Lam.) Mart.

Table 1. Samples data of Xylopia aromatica (Lam.) Mart.

\begin{tabular}{lcrcc}
\hline Área & SPw & $\begin{array}{c}\text { Altura } \\
(\mathrm{m})\end{array}$ & $\begin{array}{c}\text { Perímetro } \\
(\mathrm{cm})\end{array}$ & $\begin{array}{c}\text { Diâmetro das raizes } \\
(\mathrm{cm})\end{array}$ \\
\hline \multirow{4}{*}{ Cerrado } & 1918 & 10 & 34,50 & $4,00 \times 3,00$ \\
& 1919 & 10 & 40,50 & $4,00 \times 4,50$ \\
& 1937 & 8 & 38,50 & $5,00 \times 6,00$ \\
& 1859 & 8 & 33,00 & $4,00 \times 2,50$ \\
Plantio & 1860 & 10 & 54,00 & $4,50 \times 3,50$ \\
& 1861 & 10 & 55,00 & $4,00 \times 3,00$ \\
\hline
\end{tabular}



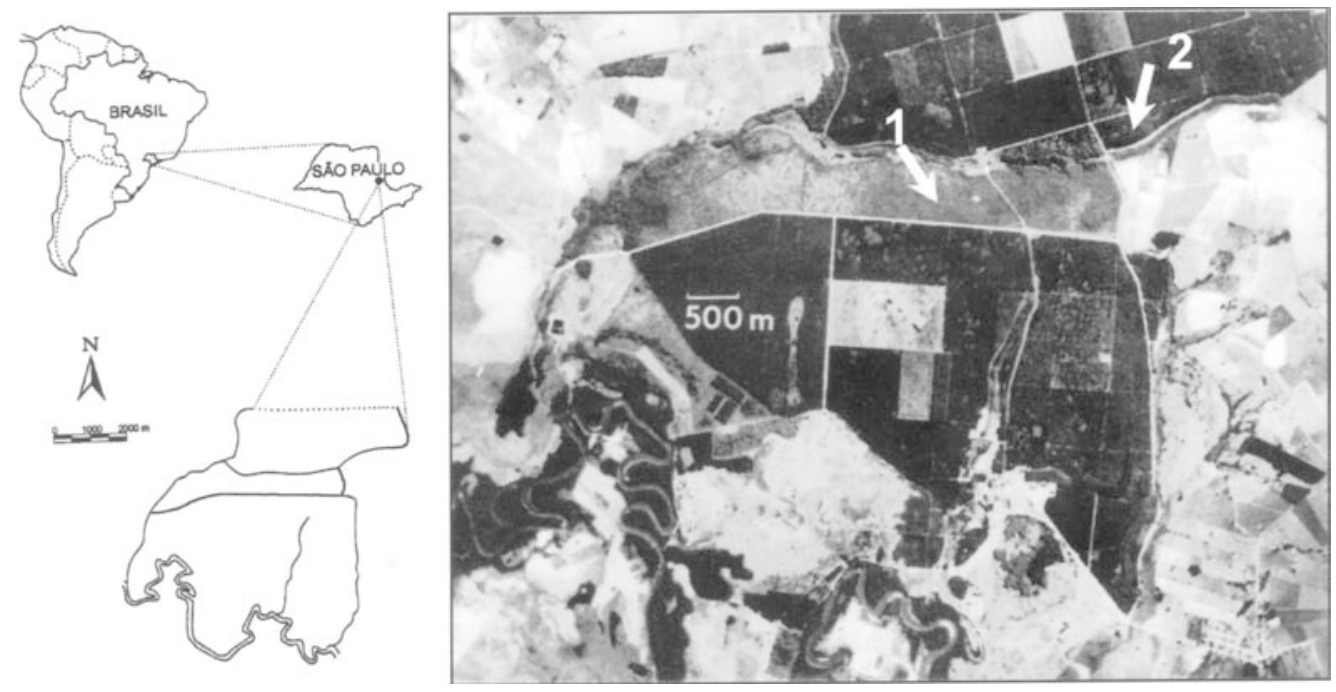

Figura 1. Localização das áreas de estudo, área do cerrado (seta 1), área do plantio (seta 2), dentro da Estação Ecológica de Moji-Guaçu, Moji-Guaçu, SP. Mapa segundo Giudice Neto (1999) e foto aérea conforme Delitti (1982), modificados.

Figure 1. Localization of studied areas in "cerrado" (arrow 1) and plantation (arrow 2) in Estação Ecológica de Moji-Guaçu, Moji-Guaçu, SP. Map by Giudice Neto (1999) and photo after Delitti (1982), modified.

Os dados quantitativos, foram obtidos mediante contagens e medições do tecido macerado e das seções histológicas, referentes a 18 características anatômicas, envolvendo vasos, fibras, parênquima axial e radial, de cada um dos espécimes. Esses dados foram submetidos à prova não paramétrica de Mann-Whitney, equivalente ao teste de duas médias para amostras independentes, a um nível de 5\% de probabilidade (Lehmann \& D'abrera 1975).

O solo das duas áreas foi analisado quanto a umidade à base de peso ( $\mu$ ) (Reichardt 1985), coletado a cada duas semanas, exceto em outubro e novembro (uma coleta) e janeiro e dezembro (três coletas), na profundidade de $0-10 \mathrm{~cm}$ em três pontos padronizados em cada uma das áreas. A amostragem em tal profundidade não fornece o perfil de umidade do solo, que implica em variações de umidade e de armazenamento de água, mas propicia dados preliminares para possível discussão.

Foram realizadas, também, análises texturais, pelo método de densitômetro; das características químicas, com terra fina seca ao ar, para as amostras dos três pontos de cada área e curva de retenção de água, através do pré secamento de amostras, utilizando Câmara de Richards, à base de peso $(\mu)$, no Departamento de Solos e Nutrição de Plantas da Escola Superior de Agricultura Luiz de Queiroz, Universidade de São Paulo.

\section{Resultados e Discussão}

Os resultados das análises de solo referentes à textura granulométrica e análise química, são apresentadas nas tabelas 2 e 3 , respectivamente.
Tabela 2. Análise granulométrica (método do Densímetro).

Table 2. Granulometric analysis (Densimeter method).

\begin{tabular}{lccccc}
\hline Área & Ponto & $\begin{array}{c}\text { Areia } \\
(\%)\end{array}$ & $\begin{array}{c}\text { Silte } \\
(\%)\end{array}$ & $\begin{array}{c}\text { Argila } \\
(\%)\end{array}$ & Classe de textura \\
\hline \multirow{4}{*}{ Cerrado } & 1 & 74 & 4 & 22 & média arenosa \\
& 2 & 78 & 2 & 20 & média arenosa \\
& 3 & 78 & 2 & 20 & média arenosa \\
& 1 & 76 & 2 & 22 & média arenosa \\
Plantio & 2 & 76 & 2 & 22 & média arenosa \\
& 3 & 78 & 2 & 20 & média arenosa \\
\hline
\end{tabular}

Quanto à granulometria, os solos não apresentam nenhuma diferença, pois as duas áreas são caracterizadas por solo de cerrado.

Quanto à análise química, somente o cálcio e a matéria orgânica apresentaram resultados variados. $\mathrm{O}$ cálcio apresentou maior concentração no solo do plantio, provavelmente transferido pelas folhas do pinhal, superando aquelas do cerrado (Delitti 1982).

A matéria orgânica teve os maiores valores observados nas amostras do cerrado. Essa diferença provavelmente é devida ao tipo de cobertura vegetal apresentado em cada uma das áreas, o que nos leva a concluir que o florestamento por Pinus elliottii Engel. pode acentuar o empobrecimento dos solos de cerrados, já caracterizados por uma fertilidade muito baixa (Setzer 
Tabela 3. Características químicas do solo à $10 \mathrm{~cm}$ de profundidade nas áreas de cerrado (C) e de plantio (P).

Table 3. "Cerrado" $(\mathrm{C})$ and plantation $(\mathrm{P})$ soil chemistries characteristcs at $10 \mathrm{~cm}$ depth.

\begin{tabular}{cccccccc}
\hline Amostra & $\begin{array}{c}\mathrm{pH} \\
\end{array}$ & \multicolumn{1}{c}{$\mathrm{Al}+\mathrm{H}$} & $\mathrm{Ca}$ & $\mathrm{Mg}$ & $\mathrm{K}$ & $\begin{array}{c}\mathrm{P} \\
\left.\mathrm{mg} \mathrm{kg}_{2} \mathrm{O}\right)\end{array}$ & \multicolumn{3}{c}{$\begin{array}{c}\text { M.O. } \\
\mathrm{g} \mathrm{kg}^{-1}\end{array}$} \\
\hline $\mathrm{C} 1$ & 3,9 & 71 & 2 & 2 & 0,9 & 5 & 23 \\
$\mathrm{C} 2$ & 3,8 & 78 & 1 & 1 & 0,8 & 9 & 26 \\
$\mathrm{C} 3$ & 3,9 & 71 & 2 & 1 & 0,9 & 6 & 23 \\
$\mathrm{P} 1$ & 4,0 & 68 & 3 & 2 & 0,8 & 5 & 20 \\
$\mathrm{P} 2$ & 4,1 & 69 & 4 & 2 & 0,6 & 4 & 18 \\
$\mathrm{P} 3$ & 3,8 & 80 & 2 & 2 & 0,5 & 5 & 18 \\
\hline
\end{tabular}

1949, Comissão de solos 1960). Esse fato é corroborado pela baixa quantidade de transferência de nutrientes de serapilheira de Pinus elliottii, observado em uma floresta implantada nessa mesma região (Delitti 1982).

A umidade do solo (figura 2) compreendida entre os dois níveis de retenção $(0,33$ e 15 atm), representa a água disponível no solo a $10 \mathrm{~cm}$ de profundidade e os valores abaixo da curva de 15 atm o déficit hídrico. Os valores acima da curva de $0,33 \mathrm{~atm}$ representariam o excesso de água, que não foram observados nesta análise.

Nota-se que na área do cerrado ocorreu um período contínuo de déficit hídrico de abril a novembro, observando-se também um pequeno déficit no início de janeiro e outro no final de fevereiro.

Para a área de plantio, o déficit observado foi da segunda quinzena de março à primeira de setembro, porém interrompido, na segunda quinzena de maio e segunda de junho, por valores de umidade dentro do limite de água disponível, semelhante aos demais meses.

A análise comparativa dos dados de umidade e da curva de retenção de água mostra que o solo de cerrado passa por período maior de déficit hídrico que o solo de plantio, fato observado pela maior área entre os dois níveis de retenção, correspondendo à água disponível no solo.

Esse maior período de déficit hídrico, do cerrado, pode ser devido a uma maior cobertura arbórea, que oscila entre 50\% a 90\% (Ribeiro \& Walter 1998). Já no plantio de Pinus, além do espaçamento entre os espécimes ser muito maior, após quatro desbastes, restaram apenas $3,75 \%$ da plantação inicial.

Apesar da maioria das plantas lenhosas apresentarem sistema radicular profundo, tendo acesso
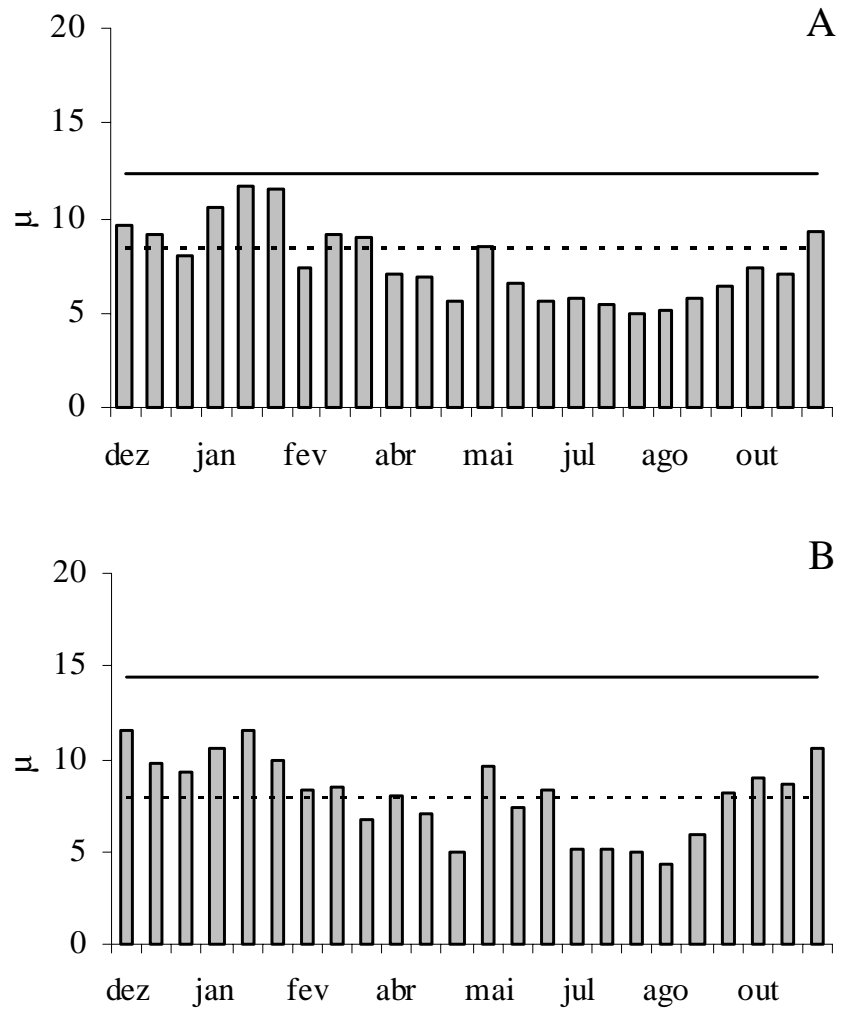

Figura 2. Média da umidade do solo $(\mu)$ das duas áreas: cerrado (A) e plantio (B); curva de retenção da água a 15 atm (---) e 0,33 atm (-) para cada área.

Figure 2. Means of soil moisture $(\mu)$ from both area: "cerrado" (A) e plantation (B); water retention curves in $15 \mathrm{~atm}$ (---) and $0,33 \mathrm{~atm}(-)$ for each area.

às reservas de água do subsolo, algumas espécies apresentam um sistema radicular superficial (Jackson et al. 1999); e a redução da disponibilidade de água nas camadas superficiais do solo, refletindo o déficit sazonal por que passa essa região, caracterizada pela presença de uma estação seca de 4 a 6 meses de duração, foi confirmada por Luchi (1998).

A tabela 4 mostra os resultados das provas de Mann-Whitney para as variáveis anatômicas do caule e da raiz. Para as 18 variáveis quantificadas, o caule apresentou 12 médias diferentes, ao nível de 5\% de significância, entre as condições de solo de cerrado e de plantio de Pinus elliottii, e para a raiz as diferenças foram constatadas em nove médias.

A figura 3 apresenta o gráfico com as médias das variáveis significativamente diferentes entre si para o cerrado e para o plantio, referente ao caule (figuras $3 \mathrm{~A}, \mathrm{~B}$ ) e à raiz (figuras $3 \mathrm{C}, \mathrm{D}$ ).

Observa-se que, para o caule, as árvores do cerrado apresentam médias maiores que aquelas do plantio, para 
Tabela 4. Resultado da prova de Mann-Whitney ( $<<0,05)$.

Table 4. Results of Mann-Whitney proof $(\mathrm{p}<0,05)$.

Freqüência de vasos

Diâmetro de vasos

Comprimento de elemento de vasos

Diâmetro das pontoações intervasculares

Diâmetro das pontoações radiovasculares

Freqüência de raios

Altura dos raios (mm)

Altura dos raios (número de células)

Largura dos raios $(\mu \mathrm{m})$

Largura dos raios (células)

Comprimento das fibras

Diâmetro das fibras

Diâmetro do lume das fibras

Espessura da parede das fibras

Porcentagem de parênquima axial

Porcentagem de vasos

Porcentagem de fibras

Porcentagem de raios
$0,0000 *$
0,3159
0,0188 *
$0,0000 *$
$0,0005 *$
0,0174 *
$0,0007 *$
$0,0001 *$
0,0025 *
0,3387
0,0000 *
0,4165
0,0447
$0,0000 *$
0,0013 *
0,0000 *
0,1597
0,5410
0,7383
0,1940
0,9635
$0,0000 *$
$0,0003 *$
0,0515
0,0034 *
$0,0004 *$
0,1622
0,0789
0,0000 *
0,0594
0,0184 *
$0,0000 *$
$0,0001 *$
$0,0048 *$
0,4424
0,0567

* = significante a $5 \%$

nove características, algumas observadas nas figuras 4-13.

Segundo Baas et al. (1983), espécies de ambientes secos tendem a aumentar a freqüência dos vasos de menor diâmetro, aliando o fator eficiência ao de segurança. Entretanto, apesar da frequiência de vasos ter se apresentado com médias maiores para os indivíduos da área de cerrado, não foram observadas diferenças significantes entre os diâmetros dos elementos de vasos dos indivíduos dos dois ambientes (figuras 4, 5, tabela 4).

Dessas nove características, quatro estão relacionadas aos raios: frequiência de raios, altura dos raios em milímetro, altura dos raios em número de células e largura dos raios em micrometro (figuras 8, 9).

Läuchli (1972) atribuiu ao parênquima radial a função de transporte de íons entre xilema e floema. Entretanto Braun (1984) propôs que os dois tipos de parênquima, axial e radial, constituem tecidos acessórios aos elementos condutores, cuja principal função seria originar maior força osmótica dentro dos vasos através da mobilização de substâncias osmoticamente ativas, aumentando o fluxo nos vasos, favorecendo, assim, as espécies que as apresentam.

Apesar dos trabalhos, como os de Baas (1973), Fahn et al. (1986), dentre outros, não mostrarem nenhuma relação entre a largura dos raios e os fatores ambientais, há indícios de que as espécies que apresentam raios mais largos estão sujeitas a um ambiente hidricamente desfavorável, fato corroborado por Outer \& Veenendaal (1976) que obtiveram os maiores valores de largura de raios nas espécies de savana e Luchi (2004a) em espécimes de Croton urucurana Baill. de área mais seca.

Fibras com paredes mais espessas são freqüentes em ambientes mais secos. Fahn et al. (1986), através de dados da flora de Israel, observaram fibras de paredes mais espessas nas espécies mediterrâneas e nas do deserto; Alves \& Angyalossy-Alfonso (2002) observaram a mesma tendência em ambientes com menor grau de umidade; Luchi (2004a) obteve médias estatisticamente maiores para espécimes de Croton urucurana da área mais seca, corroborando os dados obtidos neste trabalho (figuras 6,7).

Com relação à porcentagem de vasos, característica praticamente não abordada na literatura, Luchi (1998) obteve as maiores médias para Eugenia repanda O. Berg e para Croton urucurana (Luchi 2004a), ambas espécies de áreas caracterizadas com maior disponibilidade hídrica, resultados que divergem dos dados aqui apresentados.

Os resultados obtidos para o comprimento dos 


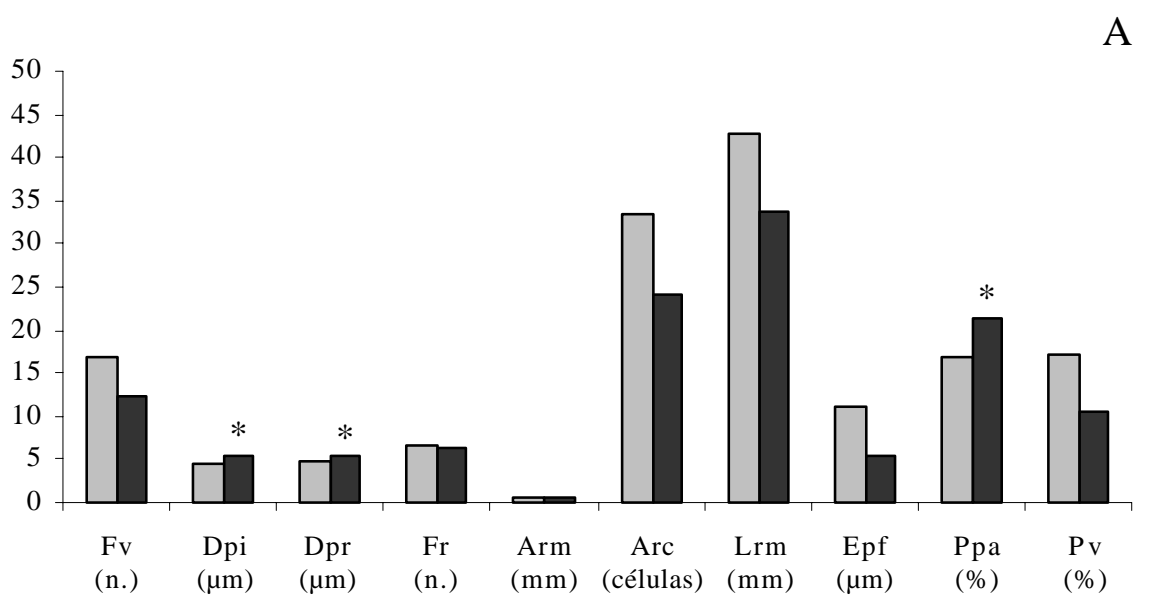

A
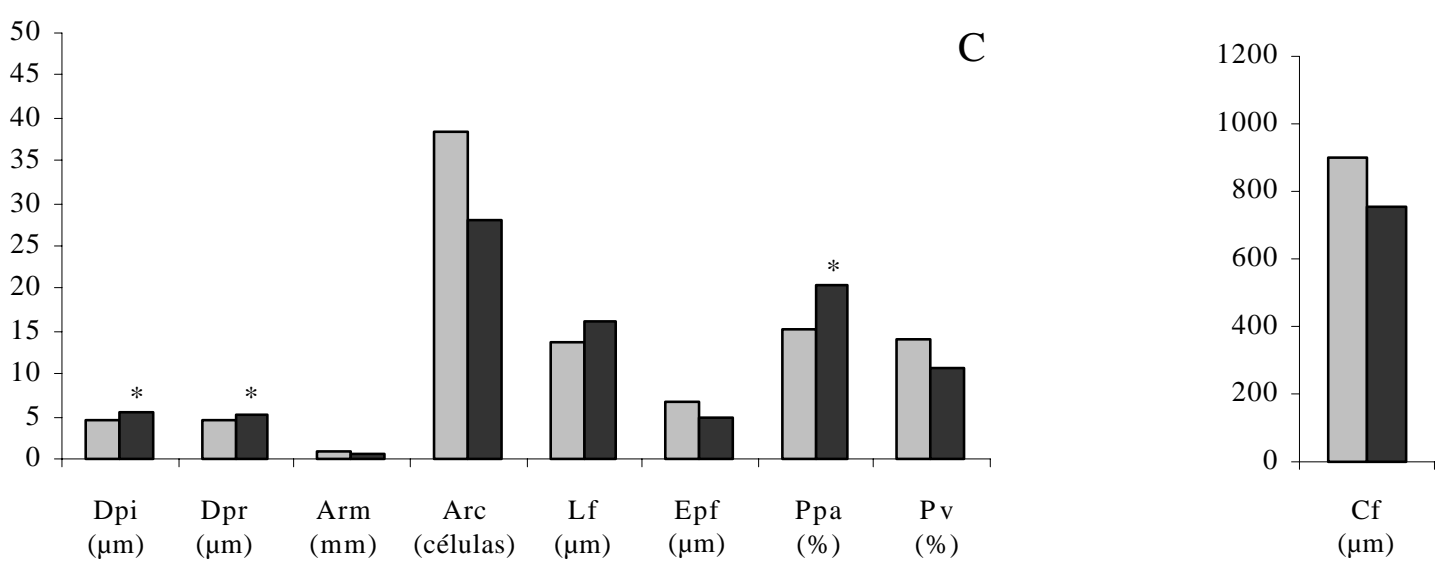

Figura 3. Resultado da prova de Mann-Whytney, em que as médias de cada característica anatômica significativa são

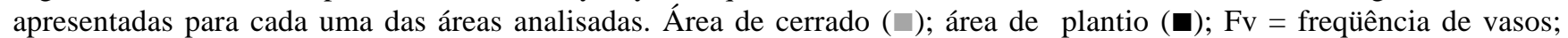
Dpi $=$ diâmetro das pontoações intervasculares; $\mathrm{Dpr}=$ diâmetro das pontoações radiovasculares; $\mathrm{Fr}=$ frequiência de raio; Arm $=$ altura dos raios em milímetros; Arc $=$ altura dos raios em células; $\mathrm{Lrm}=$ largura dos raios em micrômetros; Epf $=$ espessura da parede da fibra; $\mathrm{Ppa}=$ porcentagem de parênquima axial; $\mathrm{Pv}=$ porcentagem de vasos; $\mathrm{Cv}=$ comprimento dos elementos de vasos; $\mathrm{Cf}=$ comprimento das fibras. ${ }^{*}=$ médias maiores para os espécimes da área do plantio). As médias foram separadas em grupos A e B (caule), C e D (raiz) para melhor acomodar as escalas.

Figure 3. Results of Mann-Whytney proof for each significant anatomical feature for each analyzed area. "Cerrado" area ( $\square$ ); plantation area ( $\mathbf{\square}) ; \mathrm{Fv}=$ vessel per square millimetre; $\mathrm{Dpi}=$ intervessel pits diameter; $\mathrm{Dpr}=$ vessel-ray pits diameter; $\mathrm{Fr}=\mathrm{ray}$ per millimetre; Arm = height ray in micrometer; Arc = height ray in cells; $\mathrm{Lrm}=$ ray width in micrometer; Epf $=$ fibre wall thickness; $\mathrm{Ppa}=$ axial parenchyma percentage; $\mathrm{Pv}=$ vessel percentage; $\mathrm{Cv}=$ vessel element length; $\mathrm{Cf}=$ fibre length; $(*=$ greater means for plantation area). The means were in different groups: $\mathrm{A}$ and B (stem), C and D (root) to adapt the scales.

Figures 4-13. Stem of Xylopia aromatica. 4-7. Transverse sections. 4. "Cerrado" area specimen, note growth ring boundary (long arrow), axial parenchyma (short arrow) and secretory idioblast (*). 5. Plantation specimen, growth ring boundary (long arrow), axial parenchyma (short arrow). 6-7. Transverse sections showing fibre wall thickness. 6. "Cerrado" area specimen. 7. Plantation specimen. 8-9. Tangential sections, note heigth ray (r). 8. "Cerrado" area specimen. 9. Plantation specimen. 10-11. Tangencial sections with intervessel pits. 10. "Cerrado" area specimen. 11. Plantation specimen. 12-13. Radial sections with vessel-ray pits. 12. "Cerrado" area specimen. 13. Plantation specimen. Bars $=100 \mu \mathrm{m}(4-5,8-9), 20 \mu \mathrm{m}(6-7)$ and $10 \mu \mathrm{m}$ (10-11). 

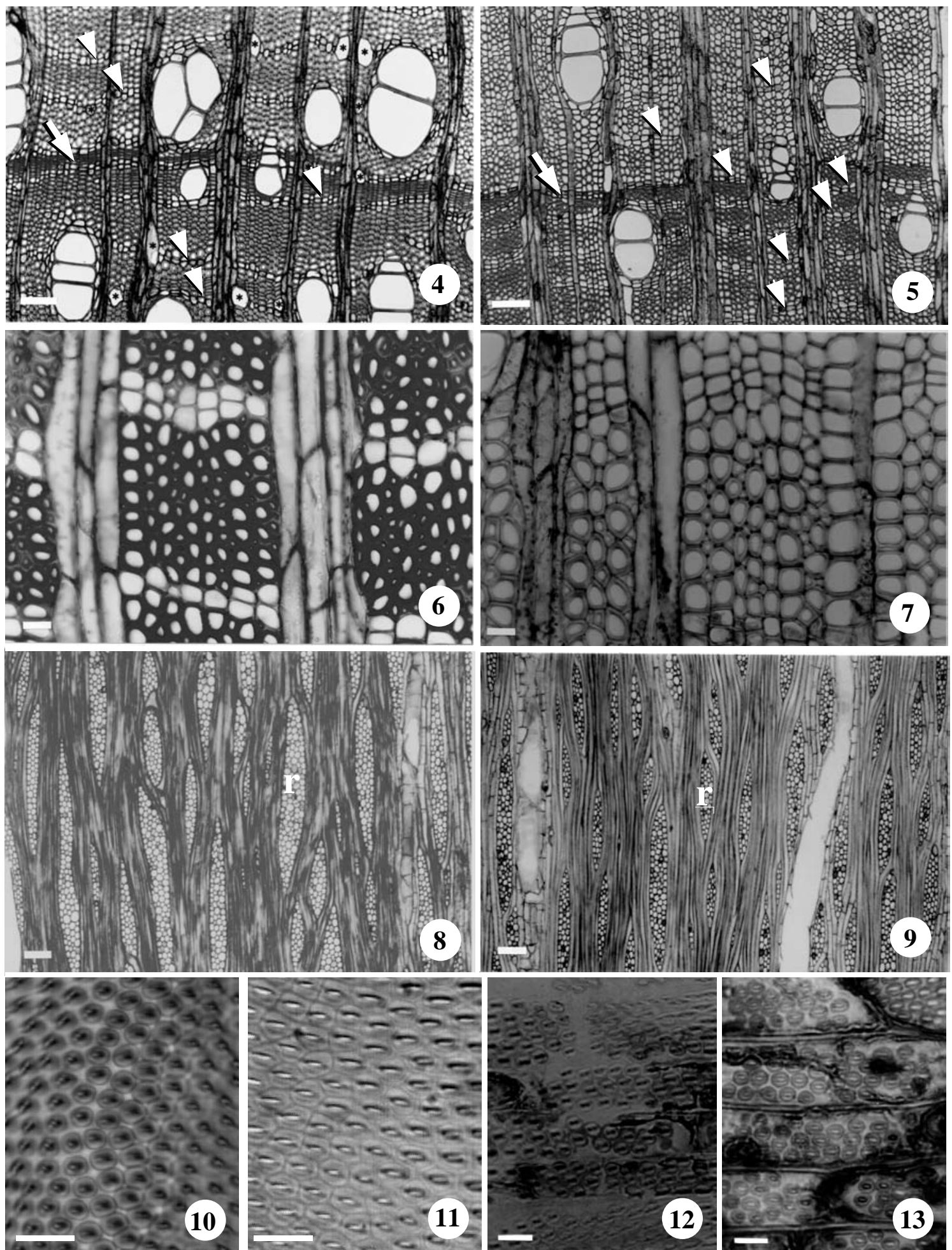

Figuras 4-13. Caule de Xylopia aromatica. 4-7. Seções transversais. 4. Espécime da área de cerrado, observar delimitação da camada de crescimento (seta longa), parênquima axial (seta curta) e presença de idioblasto secretor (*). 5. Espécime da área de plantio, com a delimitação da camada de crescimento (seta longa), parênquima axial (seta curta). 6-7. Seções transversais mostrando o espessamento das paredes das fibras. 6. Espécime da área de cerrado. 7. Espécime da área de plantio. 8-9. Seções longitudinais tangenciais, evidenciando a altura dos raios (r). 8. Espécime da área de cerrado. 9. Espécime da área de plantio. 10-11. Seções longitudinais tangenciais de elemento de vaso, pormenorizando as pontoações intervasculares. 10. Espécime da área de cerrado. 11. Espécime do plantio. 12-13. Seções longitudinais radiais, em que são pormenorizadas as pontoações radiovasculares. 12. Espécime da área de cerrado. 13. Espécime da área de plantio. Barras = $100 \mu \mathrm{m}(4-5,8-9), 20 \mu \mathrm{m}(6-7)$ e $10 \mu \mathrm{m}(10-11)$. 
elementos de vaso e comprimento das fibras, contrariam dados obtidos anteriormente por Luchi (1998) em Guarea macrophylla Vahl, Psychotria carthagenensis Jacq., Eugenia repanda e Inga vera Wild. ocorrentes em ambiente com maior grau de umidade, assim como aqueles obtidos por Carlquist \& Hoekman (1985), que registraram elementos de vasos mais longos em espécimes de ecossistemas mésicos, e Baas et al. (1983) em espécies higrófilas.

As árvores do plantio apresentaram $25 \%$ das médias estatisticamente diferentes (figura 3), ou seja, apenas 3 variáveis - Diâmetro das pontoações intervasculares - Dpi (figura 11), Diâmetro das pontoações radiovasculares - Dpr (figura 13) e Porcentagem de parênquima axial - Ppa (figuras 5), apresentaram médias maiores que aquelas do cerrado.

$\mathrm{O}$ diâmetro das pontoações intervasculares e o das radiovasculares (figuras 10-13), são outras duas características pouco abordada na análise com o ambiente, pois alguns pesquisadores consideram-nas como conservativas para as espécies. Entretanto, Luchi (2004a), analisando caule de Croton urucurana de solos com diferentes níveis de umidade, constatou as maiores médias somente para as pontoações intervasculares, nos indivíduos da área alagada. O presente trabalho constatou as maiores médias, nos espécimes de $X$. aromatica da área de plantio, para os dois tipos de pontoações intervasculares e radiovasculares (figuras 11,13).

Quanto ao parênquima axial, alguns trabalhos relacionam sua maior abundância nos espécimes de ambientes mais secos, como os do deserto (Fahn et al. 1986), das baixas latitudes (Wilkins \& Papassotiriou 1989), que representam condições ambientais mais xéricas, e de caatinga (Alves \& Angyalossy-Alfonso 2002). Deve-se ressaltar que os espécimes da área de plantio, aqui analisados, estão em solo de cerrado, sujeitos aos períodos de seca anual característicos da região (Luchi 1998).

Quanto à raiz, as árvores do cerrado apresentam médias maiores que aquelas da área de plantio para cinco variáveis (Altura dos raios em milímetros - Arm, Altura dos raios em número de células - Arc, Espessura da parede das fibras - Epf, Porcentagem de vasos - Pv e Comprimento das fibras - Cf) (figuras 14-23), características que variaram de forma semelhante no lenho do caule desses mesmos espécimes.

A maior altura dos raios, em milímetro e em número de células (figuras 18, 19), corrobora a análise de que as espécies que as apresentam estão sujeitas a um ambiente hidricamente mais desfavorável.

A maior porcentagem de vasos, constatada nas raízes de $X$. aromatica (Lam.) Mart. da área de cerrado, difere dos dados de Luchi (2004b), em que a mesma característica não foi significante para as raízes dos espécimes de Croton urucurana de três áreas com diferentes níveis de umidade.

No presente estudo, as características relacionadas às fibras, como comprimento e espessura de parede, se contrapõem a dados da literatura, pois paredes de fibras espessas estão associadas a ambientes secos (Fahn et al. 1986, Alves \& Angyalossy-Alfonso 2002), enquanto que fibras mais longas estão associadas a ambientes com maior disponibilidade hídrica (Baas et al. 1983, Carlquist \& Hoekman 1985).

Para a raiz das árvores do plantio, quatro variáveis apresentaram as maiores médias (figura 3 ) - pontoações intervasculares (figuras 20,21), pontoações radiovasculares (figuras 22,23 ) e porcentagem de parênquima axial (figuras 14, 15) e o diâmetro do lume das fibras (figuras 16,17).

O diâmetro das pontoações intervasculares e o das radiovasculares, apesar de serem consideradas características conservativas, como já comentado, ocorreram concomitantemente nas raízes e nos caules das árvores da área do plantio com as maiores médias. Este aspecto reforça a interpretação da interferência do plantio nessas características, pois Luchi (2004b) relatou as maiores médias, somente para as pontoações intervasculares, nas raízes de C. urucurana da área seca.

Como também já comentado, a abundância do parênquima axial no caule está relacionada a espécimes de ambientes mais secos (Fahn et al. 1986, Wilkins \& Papassotiriou 1989, Alves \& Angyalossy-Alfonso 2002).

Figures 14-23. Root of Xylopia aromatica. 14-17. Transverse sections. 14. "Cerrado" area specimen, note growth ring boundary (long arrow), axial parenchyma (short arrow), and secretory idioblast (*). 15. Plantation area specimen, note growth ring boundary (long arrow), axial parenchyma (short arrow). 16-17. Transverse sections showing fibre wall thickness. 16. "Cerrado" area specimen. 17. Plantation area specimen. 18-19. Tangential sections, note heigth ray (r). 18. "Cerrado" specimen. 19. Plantation specimen. 20-21. Tangential sections with intervessel pits. 20. "Cerrado" specimen. 21. Plantation specimen. 22-23. Radial sections with vessel-ray pits. 22. "Cerrado" specimen. 23. Plantation specimen. Bars = $100 \mu \mathrm{m}(14-15,18-19), 20 \mu \mathrm{m}(16-17)$ and 10 $\mu \mathrm{m}$ (20-23). 

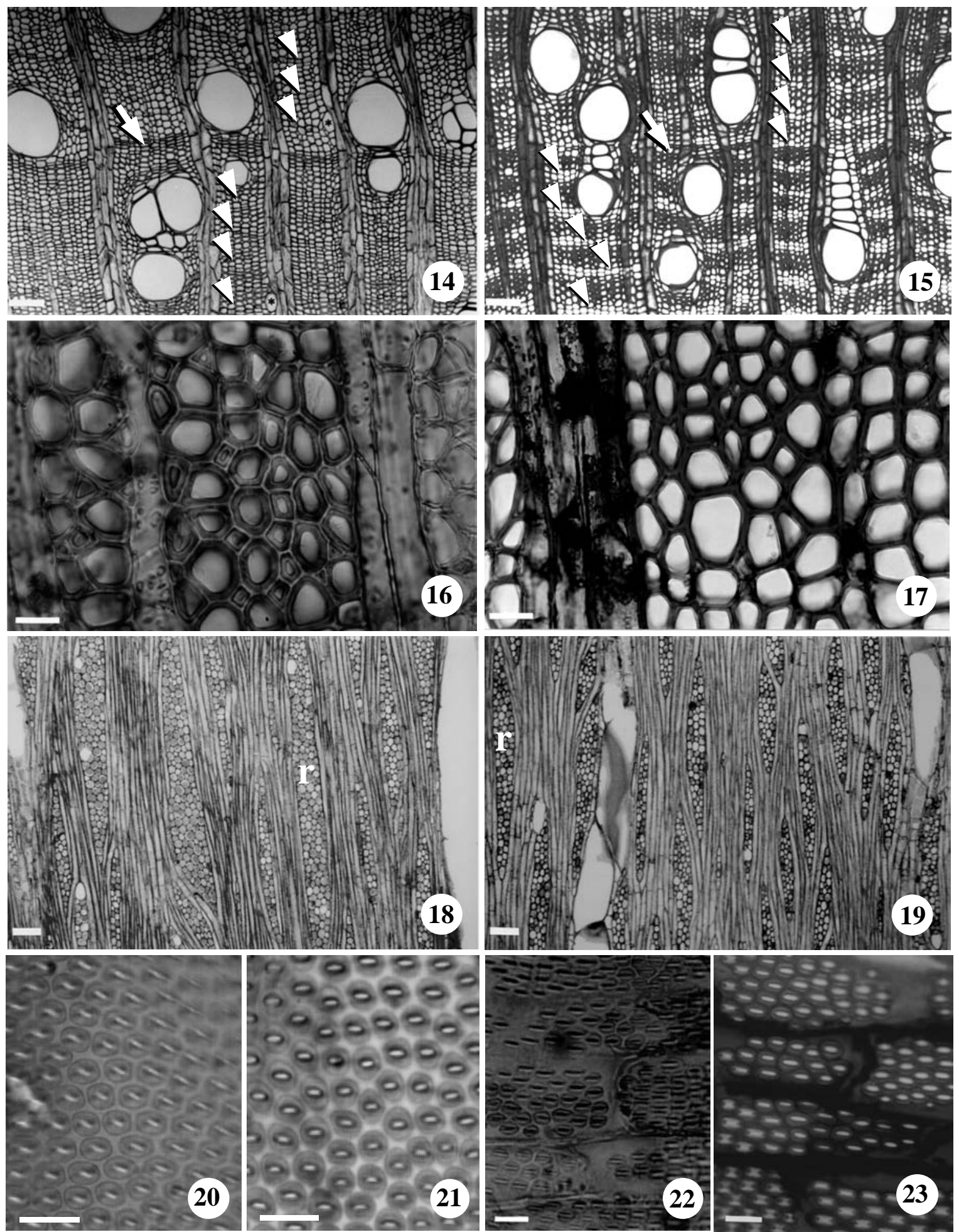

Figuras 14-23. Raiz de Xylopia aromatica. 14-17. Seções transversais. 14. Espécime da área de cerrado, observar delimitação da camada de crescimento (seta longa), parênquima axial (seta curta) e presença de idioblasto secretor (*). 15. Espécime da área de plantio, com a delimitação da camada de crescimento (seta longa), parênquima axial (seta curta). 16-17. Seções transversais mostrando o espessamento das paredes das fibras. 16. Espécime da área de cerrado. 17. Espécime da área de plantio. 18-19. Seções longitudinais tangenciais, observar a altura dos raios ( r ). 18. Espécime da área de cerrado. 19. Espécime da área de plantio. 20-21. Seções tangenciais com pontoações intervasculares. 20. Espécime da área de cerrado. 21. Espécime do plantio. 22-23. Seções radiais com pontoações radiovasculares. 22. Espécime da área de cerrado. 23. Espécime da área de plantio. Barras $=100 \mu \mathrm{m}(14-15,18-19), 20 \mu \mathrm{m}(16-17)$ e $10 \mu \mathrm{m}(20-23)$. 
Sobre sua ocorrência nas raízes os dados são praticamente inexistentes na literatura, exceto no que foi apontado por Luchi (2004b) que constatou, em C. urucurana, uma maior quantidade de parênquima axial nas raízes dos indivíduos das áreas úmida e seca, com dados percentuais estatísticos nessa mesma ordem.

Quanto ao diâmetro de lume das fibras, característica não significante para o caule de $X$. aromatica, foi observada também na raiz de C. urucurana (Luchi 2004b) das árvores da área seca. Entretanto, no caule dessa mesma espécie (Luchi 2004a), a característica apresentou-se estatisticamente significante para os espécimes das áreas úmida e alagada, com os mesmos parâmetros de significância. Observou-se que, na raiz de $X$. aromatica, a espessura da parede da fibra apresentou-se estatisticamente menor para as árvores do plantio, acarretando, portanto, um maior lume das paredes das fibras, uma vez que os diâmetros não foram estatisticamente diferentes.

Características não mensuradas foram também constatadas entre os espécimes analisados. Uma delas é a presença de anéis de crescimento observados nos caules e nas raízes, tanto dos espécimes do cerrado, quanto nos do plantio (figuras 4, 5, 14, 15). Observa-se também a diminuição no diâmetro dos elementos de vaso próximos à delimitação do anel de crescimento. Essas duas características enfatizam uma adaptação fisiológica e anatômica desses espécimes ao período de seca pelo qual passa a região (Luchi 1998).

Outra característica notada, refere-se à aparente maior frequiência de idioblastos nos caules dos espécimes do cerrado (figura 4), fato de grande importância, pois a literatura relata, em Xylopia aromatica, a ocorrência de óleos essenciais - terpenóides (Moraes \& Roque 1988, Martins et al. 1998, Martins et al. 1999) cujas propriedades bacteriostáticas e antifúngicas são de interesse na indústria cosmética e farmacêutica. Esse caráter está provavelmente relacionado ao maior déficit hídrico na área de cerrado, pois Sousa (1977), trabalhando com folhas de Xylopia aromatica provenientes de quatro localidades diferentes, obteve os mais altos valores de limoneno (10,2\%) e sesquiterpenos $(48,2 \%)$ nas folhas de espécimes de Moji-Guaçu. O autor discute, ainda, a influência dos fatores ambientais refletidos na composição química do óleo essencial, pelo fato de que as folhas com menor concentração de terpenos pertencerem a indivíduos de região com pluviosidade relativamente elevada e de solo com alta retenção de água.

Os resultados aqui apresentados dão indícios do efeito da presença de Pinus elliottii, em solo de cerrado, sobre as características anatômicas, precedidas, conseqüentemente, pelas fisiológicas, nos exemplares de Xylopia aromatica desenvolvidos naturalmente dentro dessa plantação.

Agradecimentos - Ao Sr. Paulo Barbosa da Silva, Oficial de Apoio à Pesquisa Científica e Tecnológica, da Reserva Biológica e Estação Experimental de Moji-Guaçu, pelo inestimável auxílio e assessoria nos trabalhos de campo.

\section{Referências bibliográficas}

ALVES, E.S. \& ANGYALOSY-ALFONSO, V. 2000. Ecological trends in the wood anatomy of some Brazilian species. I: Growthrings and vessels. IAWA Journal 21:3-30.

ALVES, E.S. \& ANGYALOSSY-ALFONSO, V. 2002. Ecological trends in the wood anatomy of some Brazilian species. 2. Axial parenchyma, rays and fibres. IAWA Journal 23:391-418.

BAAS, P. 1973. The wood anatomical range in Ilex (Aquifoliaceae) and its ecological and phylogenetic significance. Blumea 21:193-258.

BAAS, P. \& SCHWEINGRUBER, F.H. 1987. Ecological trends in the wood anatomy of trees, shrubs and climbers from Europe. IAWA Bulletin new series 8:245-274.

BAAS, P., WERKER, E.E. \& FAHN, A.1983. Some ecological trends in vessel characters. IAWA Bulletin new series 4:141-159.

BARAJA-MORALES, J. 1985. Wood structural differences between trees of two tropical forests in Mexico. IAWA Bulletin new series 6:355-364.

BRASIL, M.A.M., MONTAGNA, R.G. \& TIMONI, J.L. 1980. Densidade básica do Pinus elliottii Engelm. var. elliottii - Mogi-Guaçu, Estado de São Paulo.Boletim Técnico do Instituto Florestal 34:1-16.

BRAUN, H.J. 1984. The significance of accessory tissues of the hydrosystem for osmotic water shifting as the second principle of water ascent, with some thoughts concerning the evolution of trees. IAWA Bulletin new series 5:275-294.

CARLQUIST, S. 1975. Ecological strategies in xylem evolution. University of California Press, Berkeley.

CARLQUIST, S. \& HOEKMAN, D.A. 1985. Ecological wood anatomy of the southern California flora. IAWA Bulletin new series 6:319-347.

COMISSÃO DE SOLOS. 1960. Levantamento e reconhecimento dos solos do Estado de São Paulo. S.N.P.A. Boletim n. 12, Ministério da Agricultura, Rio de Janeiro.

DELITTI, W.B.C. 1982. Aspectos dinâmicos da serapilheira de uma floresta implantada de Pinus elliottii Engelm. var. elliottii. Dissertação de mestrado, Instituto de Biociências, Universidade de São Paulo, São Paulo. 
DIAS, B.F.S. 1994. Conservação da natureza no cerrado brasileiro. In Cerrado: caracterização, ocupação e perspectivas (M.N. Pinto, org.). Editora Universidade de Brasília, Brasília, p.583-640.

FAHN, A., WERKER, E. \& BAAS, P. 1986. Wood Anatomy and Identification of Trees and Shrubs from Israel and Adjacent Regions. The Israel Academy of Sciences and Humanities, Jerusalem.

GIUDICE NETO, J. 1999. Estrutura genética por isoenzimas em populações naturais de Jacarandá Paulista (Machaerium villosum Vog.) Dissertação de mestrado, Escola Superior de Agricultura "Luiz de Queiroz", Piracicaba.

GOLFARI, L. 1967. Coníferas aptas para repoblaciones forestales em el Estado de São Paulo. Silvicultura em São Paulo 6:7-62.

GOMES, A.V. \& MUÑIZ, G.I.B. 1986. Wood structure and ultrastructure of Prosopis caldenia, P. chilensis and $P$. juliflora and influence of ecological factors. Prosopis International Conference (M.A. Habit, ed.). FAO, Recife, p.195-216.

GOMES, B.R., MARTINS, F. \& TAMASHIRO, J. 2004. Estrutura do cerradão e da transição entre cerradão e floresta paludícola num fragmento da International Paper do Brasil Ltda., em Brotas, SP. Revista Brasileira de Botânica 27:249-262.

JACKSON, R.B., MOORE, L.A., HOFFMANN, W.H., POCKMAN, W.T. \& LINDER, C.R. 1999. Ecosystem rooting depth determined with caves and DNA. Proceedings of the National Academy of Sciences 96:11387-11392.

JOHANSEN, D.A. 1940. Plant microtechnique. MacGraw-Hill, New York.

LÄUCHLI, A. 1972. Translocation of organic solutes. Annual Review Plant Physiology and Plant Molecular Biology 23:197-218.

LEHMANN, E.L. \& D'ABRERA, H.J.M. 1975. Nonparametrics: Estatistical Methods based on ranks. Holden Day, Oakland.

LORENZI, H. 1992. Árvores Brasileiras. Manual de identificação e cultivo de plantas arbóreas nativas do Brasil. Editora Plantarum, Nova Odessa.

LUCHI, A.E. 1990. Estudo anatômico em espécies de mata ciliar da Serra do Cipó (MG). Dissertação de mestrado, Instituto de Biociências, Universidade de São Paulo, São Paulo.

LUCHI, A.E. 1998. Periodicidade de crescimento em Hymenaea courbaril L. e anatomia ecológica do lenho de espécies de mata ciliar. Tese de doutorado, Instituto de Biociências, Universidade de São Paulo, São Paulo.

LUCHI, A.E. 2004a. Anatomia do lenho de Croton urucurana Baill. (Euphorbiaceae) de solos com diferentes níveis de umidade. Revista Brasileira de Botânica 27:271-280.

LUCHI, A.E. 2004b. Anatomia do lenho de raiz de Croton urucurana Baill. (Euphorbiaceae) de solos com diferentes níveis de umidade. Hoehnea 31:243-250.
MARCATI, C.R., ANGYALOSSY-ALFONSO, V. \& BENETATI, L. 2001. Anatomia comparada do lenho de Copaifera langsdorfii Desf. (Leguminosae-Caesalpinoideae) de floresta e cerradão. Revista Brasileira de Botânica 24:311-320.

MARTINS, D., OSSHIRO, E., ROQUE, N.F., MARKS, V. \& GOTTLIEB, H.E. 1998. A sesquiterpene dimer from Xylopia aromatica. Phytochemistry 48: 677-780.

MARTINS, D., HAMERSKI, L., ALVARENGA, S.A.V. \& ROQUE, N.F. 1999. Labdane dimers from Xylopia aromatica. Phytochemistry 51:813-817.

MORAES, M.P.L. \& ROQUE, N.F. 1988. Diterpenes from the fruits of Xylopia aromatica. Phytochemistry 27:3205-3208.

MATTOS FILHO, A. 1971. Estudo comparativo entre duas espécies de Leguminosae latescentes do cerrado e da caatinga. Rodriguesia 38:9-33.

MATTOS FILHO, A. 1989. Estudo morfológico da madeira do par de espécies vicariantes de Pithecellobium anajuliae Riz. e Pithcellobium tortum Mart. (Leguminosae-Mimosoideae). Revista Brasileira de Biologia 48:143-154.

MAZZONI-VIVEIROS, S.C. \& LUCHI, A.E. 1989. Adaptações anatômicas. In: Anais do Simpósio sobre mata ciliar (L.M. Barbosa, coord.). Fundação Cargill, São Paulo, p.71-98.

NORMAND, D. 1972. Manuel d'identification des bois comerciaux. Centre Technique Forestier Tropical, Nogent-sur-Marne.

OUTER, R.W. \& VEENENDAAL, W.L.H. 1976. Variation in wood anatomy of species with a distribution covering both rain forest and savanna areas of the Ivory Coast, West-Africa. In Wood structure in biological and technological research (P. Baas, A.J. Bolton \& D.M. Catling, eds.). Leiden Botanical Series n.3. Leiden University Press, Leiden, p.182-195.

RATTER, J.A. 2004. Prefácio. In Plantas do cerrado paulista: imagens de uma paisagem ameaçada (G. Durigan, J.B. Baitello, G.A.D.C. Franco \& M.F. Siqueira, aut.). Páginas \& Letras Editora e Gráfica, São Paulo, p.vii-viii.

RATTER, J.A., BRIDGEWATER, S. \& RIBEIRO, J.F. 2003. Analysis of the floristic composition of the brazilian cerrado vegetation III: comparison of the woody vegetation of 376 areas. Edinburgh Journal of Botany 60:57-109.

REICHARDT, K. 1985. Processos de transferência no Sistema - Solo - Planta - Atmosfera. $4^{\mathrm{a}}$ ed., Fundação Cargill, Campinas.

RIBEIRO, J.F. \& WALTER, B.M.T. 1998. Fitofisionomias do bioma cerrado. In Cerrado: ambiente e flora (S.M. Sano \& S.P. Almeida, eds.). Embrapa-CPAC, Planaltina, p.89-166.

RICHARDSON, D.M. 1999. Commercial forestry and agroforestry as sources of invasive alien trees and shrubs. In Invasive species and biodiversity management (O.T. Sandlund, P.J. Schei \& A. Viken, eds.). Kluwer Academic Publishers, Dordrecht, p.237-257. 
SASS, J.E. 1951. Botanical microtechnique. The Iowa State College Press, Ames.

SETZER, J. 1946. A distribuição normal das chuvas no Estado de São Paulo. Revista Brasileira de Geografia 8:3-70.

SETZER, J. 1949. Os solos do Estado de São Paulo. Biblioteca Geográfica Brasileira, série A, publicação n. 6, IBGE, Rio de Janeiro.

SETZER, J. 1966. Atlas climático e ecológico do Estado de São Paulo. Comissão Interestadual da Bacia Paraná-Uruguai, Centrais Elétricas de São Paulo, São Paulo.
SOUSA, J.P. 1977. Análise comparativa da morfologia, anatomia e óleo essencial das folhas de Xylopia aromatica (Lamarck) Martius, provenientes de quatro localidades do Brasil. Tese de doutorado, Universidade de São Paulo, São Paulo.

WILKINS, A.P. \& PAPASSOTIRIOU, S. 1989. Wood anatomical variation of Acacia melanoxylon in relation to latitude. IAWA Bulletin new series 10:201-207.

ZILLER, S.R. 2000. A estepe gramíneo-lenhosa no segundo planalto do Paraná: diagnóstico ambiental com enfoque à contaminação biológica. Tese de doutorado, Universidade Federal do Paraná, Curitiba. 